\title{
Efeito do tratamento térmico de lodo anaeróbio sobre as características de biodegradabilidade da fração orgânica
}

\section{Effect of thermal treatment of anaerobic sludge on the biodegradability characteristics of the organic fraction}

\author{
Eduardo Sales Machado Borges \\ Engenheiro Civil. Doutor em Saneamento, Meio Ambiente e Recursos Hídricos pela Universidade Federal de Minas Gerais (UFMG). Professor da Escola \\ Agrotécnica Federal de Barbacena (EAFB) \\ Carlos Augusto de Lemos Chernicharo \\ Engenheiro Civil e Sanitarista. Doutor em Engenharia Ambiental tpela Universidade de Newcastle upon Tyne. Professor-associado do Departamento de \\ Engenharia Sanitária e Ambiental da UFMG.
}

\begin{abstract}
Resumo
O presente trabalho avalia o efeito do tratamento térmico do lodo excedente de reatores UASB sobre as características de biodegradabilidade da fração orgânica remanescente, empregando-se o biogás como fonte de energia. O tratamento térmico proporcionou a elevação da temperatura do lodo até valores próximos a $75^{\circ} \mathrm{C}$, para tempos de aquecimento de sete horas. Amostras coletadas em diferentes momentos mostraram melhoras significativas na biodegradabilidade do lodo tratado termicamente, com incrementos em 60 vezes para a DBO filtrada, de 30\% para a DBO total e 50\% para a produção de biogás. Adicionalmente, o retorno do lodo tratado termicamente para o reator UASB não prejudicou as características do efluente.
\end{abstract}

Palavras-chave: Biodegradabilidade; biogás; lodo anaeróbio; reator UASB; tratamento térmico.

\begin{abstract}
This paper aimed at evaluating the effect of thermal treatment of excess anaerobic sludge upon the biodegradability characteristics of the remaining organic fraction, using biogas generated in the wastewater treatment process as energy source. Direct burning of the biogas allowed an increase in the sludge temperature up to values close to $75^{\circ} \mathrm{C}$, for a seven-hour heating period. Samples taken at different heating times showed significant increase of the biodegradability characteristics of the thermally treated sludge, with augments of around 60 times for filtered BOD, 30\% for total BOD and 50\% for biogas production. In addition, no adverse effect on effluent quality was noticed when the thermally treated sludge was returned to the UASB reactor.
\end{abstract}

Keywords: biodegradability; biogas; anaerobic sludge; UASB reactor; thermal treatment.

\section{Introdução}

Uma consequência direta do aumento da cobertura por sistemas de tratamento de esgotos, esperada para o Brasil nos próximos anos, será o aumento na geração de lodos oriundos de tais sistemas de tratamento. Esse subproduto, tal como o esgoto, precisa ser tratado e gerenciado de forma ambientalmente correta. Adicionalmente, uma vez que o aumento da cobertura por tratamento de esgotos tem se dado, via de regra, com a utilização de sistemas anaeróbios, é preciso que se atente também para a geração de metano a partir destes sistemas.

Segundo Mulder (2001), a emissão global de metano está estimada em 500 milhões de toneladas por ano, sendo que os sistemas anaeróbios de tratamento de esgotos contribuem com cerca de 5\% deste total, ou seja, cerca de 25 milhões de toneladas. A queima deste biogás, portanto, além de ser algo estritamente necessário para se amenizarem os impactos ambientais advindos do metano, que é cerca de 20 vezes mais impactante que o gás carbônico na contribuição para o aumento do efeito estufa (EVANS, 2001; IPCC, 2001), poderá reintegrar rapidamente o carbono ao seu ciclo natural, propiciando, ainda, o seu aproveitamento como uma fonte de energia calorífica, até então pouco explorada.

No que se refere à estabilização anaeróbia da fração orgânica contida no esgoto afluente, embora os reatores UASB sejam considerados uma tecnologia já estabelecida para o tratamento de esgotos 
domésticos em regiões de clima quente, algumas limitações operacionais e de projeto ainda se fazem presentes, e há a necessidade de, portanto, trabalhá-las, almejando uma maior eficiência desses sistemas de tratamento de esgotos. Uma dessas limitações refere-se à presença, no efluente, de sólidos suspensos de difícil degradação, devendo-se, assim, buscar incrementar ou desenvolver mecanismos para a digestão destes. Especificamente, os sólidos suspensos correspondem a cerca de $50 \%$ da DQO total dos esgotos domésticos, fazendo da hidrólise a etapa limitante do processo de digestão anaeróbia (FORESTI; ZAIAT; VALLERO, 2006).

Objetivando acelerar a solubilização da matéria orgânica particulada, métodos biológicos, químicos, físicos e mecânicos podem ser empregados, tais como digestão anaeróbia, digestão aeróbia, tratamento termoquímico (em meio ácido ou básico), tratamento térmico, ozonização (ROCHER et al, 1999), ultrassom, homogeneizadores de alta pressão, moinhos de bola (MULLER, 2001), oxidação úmida, centrifugação (KEPP; SOLHEIM, 2001) e tratamento químico (DELERIS et al, 2001), dentre outros.

No processamento de lodos, o emprego de qualquer um desses métodos apresenta impacto significativo nos custos. Para os tratamentos mecânicos, físicos e biológicos, o custo provém da demanda de energia para o funcionamento de equipamentos ou geração de calor, enquanto para os tratamentos químicos os custos são originários do emprego de produtos químicos (KEEP; SOLHEIM, 2001). Todos esses métodos, porém, apresentam um ponto comum, em maior ou menor grau, que é o objetivo de melhorar as características microbiológicas, de desidratação e de degradação do lodo. Sendo assim, dentre outros fatores, é necessário que se atente para os custos de instalação, operação e manutenção potenciais, na escolha da tecnologia a ser implementada.

Muller (2001) relata que a desintegração dos sólidos presentes no lodo ainda na fase aquosa muda a estrutura e aumenta a solubilidade da matéria orgânica presente. Sequencialmente, os componentes dissolvidos podem, então, ser direcionados a um processo de degradação biológica, aumentando a eficiência na remoção da matéria orgânica e culminando no aumento da produção de biogás e redução da produção de lodo excedente (SORENSEN; THOLSTRUP; ANDREASEN, 1999; MULLER, 2001; GAVALA et al, 2002).

Noyola et al (2007) concluíram que o pré-tratamento térmico de lodo similar a lodos de descarte de um sistema de lodos ativados, entre $60^{\circ} \mathrm{C}$ e $70^{\circ} \mathrm{C}$ por um período de 60 minutos, promoveu solubilização da matéria orgânica presente. Complementarmente, conforme apresentado na Tabela 1, diversos trabalhos realizados indicam um aumento na produção de biogás após submissão dos lodos tratados termicamente à digestão anaeróbia. Nesse contexto, a maioria dos estudos reporta, como relações ótimas, temperaturas que variam de $160^{\circ}$ a $180^{\circ} \mathrm{C}$ para períodos de tratamento entre 30 e 60 minutos, enquanto para o tratamento a temperaturas moderadas (próximas a $70{ }^{\circ} \mathrm{C}$ ), seriam necessários períodos que variam de horas a dias (GAVALA et al, 2003; FERRER et al, 2008; LU et al, 2008).
No que se refere à demanda de energia, seja para o tratamento térmico do lodo ou para atender às necessidades energéticas diversas de uma estação de tratamento de esgotos, Muller (2001), Van Haandel e Lettinga (1994) e Pagliuso, Passig e Villela (2002) afirmam que é possível supri-la parcial ou totalmente a partir de fontes geradoras situadas dentro do próprio sistema de tratamento de esgotos.

Neste contexto, o presente trabalho busca avaliar o efeito do tratamento térmico de lodo anaeróbio sobre a desintegração térmica da fração orgânica remanescente. Para tanto, foi avaliado o incremento nas características de biodegradabilidade de compostos orgânicos presentes no lodo anaeróbio, empregando-se o biogás gerado em reatores UASB como fonte de energia calorífica para aquecimento do lodo.

\section{Material e Métodos}

\section{Aparato experimental}

Este trabalho foi desenvolvido no Laboratório de Instalações Piloto do Departamento de Engenharia Sanitária e Ambiental da Escola de Engenharia da Universidade Federal de Minas Gerais (UFMG).

O sistema de tratamento (Figura 1A) foi alimentado com esgoto doméstico, retirado diretamente do interceptor da margem direita do ribeirão Arrudas, na cidade de Belo Horizonte (MG). O esgoto passava pelas unidades de tratamento preliminar (cesto perfurado e caixa de areia) e por um tanque de acumulação/distribuição, localizados a montante do reator UASB. O sistema era automatizado e permitia a operação da planta em regime hidráulico transiente, de acordo com um hidrograma típico de vazões horárias.

O sistema de tratamento térmico de lodo consistia em dois reservatórios de biogás (com capacidade total de 220 L) e um reator térmico de $5 \mathrm{~L}$, conforme representação esquemática mostrada na Figura 1B. Cada reservatório de biogás era constituído por duas bombonas plásticas, uma parcialmente preenchida de água, de modo que funcionasse como um selo hídrico e evitasse vazamentos de gás, e a outra funcionando como uma cobertura flutuante, visando à acumulação do biogás produzido no reator UASB. O reator térmico foi posicionado no interior de uma camisa de isolamento, de modo a reduzir as perdas de calor.

As principais características e dados operacionais do sistema de tratamento de esgotos e de tratamento térmico de lodo estão apresentados nas Tabelas 2 e 3

\section{Parâmetros analisados}

O efeito do tratamento térmico sobre as características de biodegradabilidade da fração orgânica presente no lodo anaeróbio foi avaliado por meio de análises de $\mathrm{DBO}$ e a partir de duas metodologias distintas (método titulométrico e método manométrico, Sistema Oxitop ${ }^{\circledR}$ ), e por meio de testes de biodegradabilidade anaeróbia 
Tabela 1 - Impacto do pré-tratamento térmico de lodo primário e de lodo originário de sistemas de lodos ativados submetidos à digestão anaeróbia mesofílica

\begin{tabular}{|c|c|c|c|}
\hline Referência & Tratamento térmico & Digestão anaeróbia & Resultados \\
\hline Gavala et al (2003) & $70^{\circ} \mathrm{C}, 7 \mathrm{~d}$ & Batelada, $20 \mathrm{~d}$ & $\begin{array}{l}\text { Aumento da produção de } \mathrm{CH}_{4} \text {, de } 8,30 \text { para } 10,45 \mathrm{mmol} / \mathrm{g} \\
\mathrm{SV}_{\text {aff }}(+26 \%)\end{array}$ \\
\hline Kim et al (2003) & $121^{\circ} \mathrm{C}, 30 \mathrm{~min}$ & Batelada, $7 \mathrm{~d}$ & $\begin{array}{l}\text { Aumento da produção de biogas, de } 3.657 \text { para } 4.843 \mathrm{~L} / \mathrm{m}^{3} \\
\operatorname{LAD}_{\text {aff }}(+32 \%)\end{array}$ \\
\hline Dohanyos et al (2004) & $170^{\circ} \mathrm{C}, 60 \mathrm{~s}$ & Batelada, 20 d Termofílica & Aumento da produção de biogás (+49\%) \\
\hline Valo et al (2004) & $170^{\circ} \mathrm{C}, 60 \mathrm{~min}$ & Batelada, $24 \mathrm{~d}$ & Aumento da produção de biogás (+45\%) \\
\hline Valo et al (2004) & $170^{\circ} \mathrm{C}, 60 \mathrm{~min}$ & CSTR, $20 \mathrm{~d}$ & $\begin{array}{l}\text { Aumento da produção de } \mathrm{CH}_{4} \text {, de } 88 \text { para } 142 \mathrm{~mL} / \mathrm{g} \mathrm{DQO}_{\text {afl }} \\
(+61 \%)\end{array}$ \\
\hline Bougrier et al (2006) & $170^{\circ} \mathrm{C}, 30 \mathrm{~min}$ & Batelada, $24 \mathrm{~d}$ & $\begin{array}{l}\text { Aumento da produção de } \mathrm{CH}_{4} \text {, de } 221 \text { para } 333 \mathrm{~mL} / \mathrm{g} \mathrm{DQO}_{\text {att }} \\
(+76 \%)\end{array}$ \\
\hline Bougrier, Delgenès e Carrère (2006) & $170^{\circ} \mathrm{C}, 30 \mathrm{~min}$ & CSTR, $20 \mathrm{~d}$ & $\begin{array}{l}\text { Aumento da produção de } \mathrm{CH}_{4} \text {, de } 145 \text { para } 256 \mathrm{~mL} / \mathrm{g} \mathrm{SV}_{\text {afl }} \\
(+51 \%)\end{array}$ \\
\hline Ferrer et al (2008) & $70^{\circ} \mathrm{C}, 9 \mathrm{~h}$ & Batelada, $10 \mathrm{~d}$ & Aumento da produção de biogás $(+30 \%)$ \\
\hline Lu et al (2008) & $70^{\circ} \mathrm{C}, 2 \mathrm{~d}$ & Batelada, $13 \mathrm{~d}$ & Aumento da produção de biogás (+48\%) \\
\hline
\end{tabular}

$\mathrm{SV}_{\mathrm{af}}$ : sólidos voláteis afluentes; $\mathrm{LAD}_{\text {af }}$ : lodo ativado descartado afluente.

Fonte: Adaptado de Bougrier et al (2008).

(método manométrico, Sistema Oxitop ${ }^{\circledR}$ ). Justifica-se o uso de duas metodologias para análise de DBO pelo fato de que uma delas permite analisar o processo de biodegradação no decorrer do desenvolvimento do teste (segunda metodologia), enquanto a outra apresenta resultados somente após os cinco dias de ensaio, muito embora esta última já esteja totalmente estabelecida e aceita, sendo praticada como metodologia padrão e de referência.

As análises foram realizadas a partir de amostras brutas e filtradas. As análises de DBO (método titulométrico) foram realizadas de acordo com os procedimentos constantes no Standard Methods for the Examination of Water and Wastewater (APHA/AWWA/WEF, 1998). As análises de DBO (método manométrico, Sistema Oxitop ${ }^{\circledR}$ ) foram realizadas segundo recomendações constantes no Manual de Instruções do fabricante, seguindo ainda procedimentos constantes no Standard Methods for the Examination of Water and Wastewater (APHA/AWWA/WEF, 1998). Já os testes de biodegradabilidade anaeróbia foram realizados a partir do Sistema Oxitop ${ }^{\circledR}$, com base no manual de instruções do fabricante (WTW, 1999) e metodologia proposta por Borges (2004).

Para os testes de DBO e biodegradabilidade anaeróbia, inoculavam-se frações determinadas de esgoto e lodo in natura, respectivamente, objetivando-se garantir o desenvolvimento da atividade microbiológica nos frascos de ensaio, uma vez que as amostras de lodo foram submetidas ao tratamento térmico. Nos testes de DBO e DBO Sistema Oxitop ${ }^{\circledR}$, o esgoto foi diluído 15 e 20 vezes, respectivamente. Especificamente, no teste de DBO Sistema Oxitop ${ }^{\circledR}$, as proporções empregadas de esgoto diluído (inóculo) e lodo (substrato), foram 95 e $5 \mathrm{~mL}$, respectivamente. Deste volume total, foram transferidos 43,5 mL para os frascos de DBO, seguindo orientações do fabricante do equipamento, segundo faixas de DBO esperadas. Já nos testes de biodegradabilidade anaeróbia, os volumes utilizados de lodo não tratado termicamente (inóculo) e lodo tratado termicamente (substrato) foram 20 e $80 \mathrm{~mL}$, respectivamente.

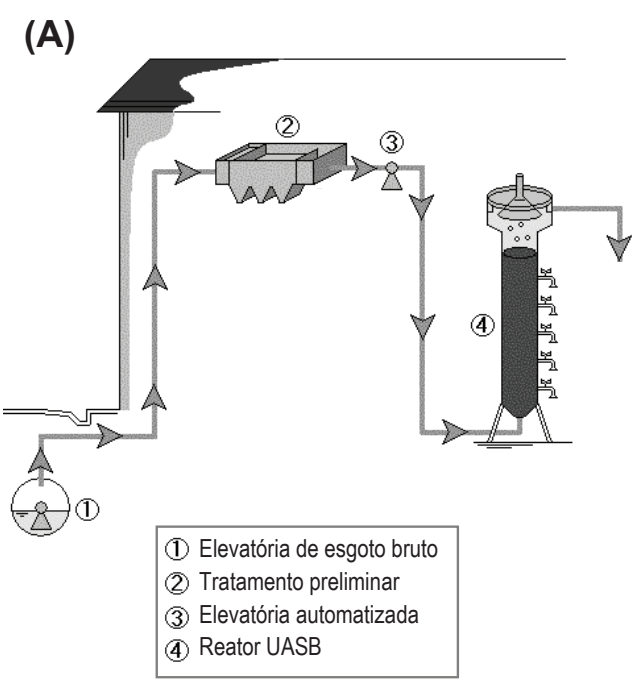

(B)

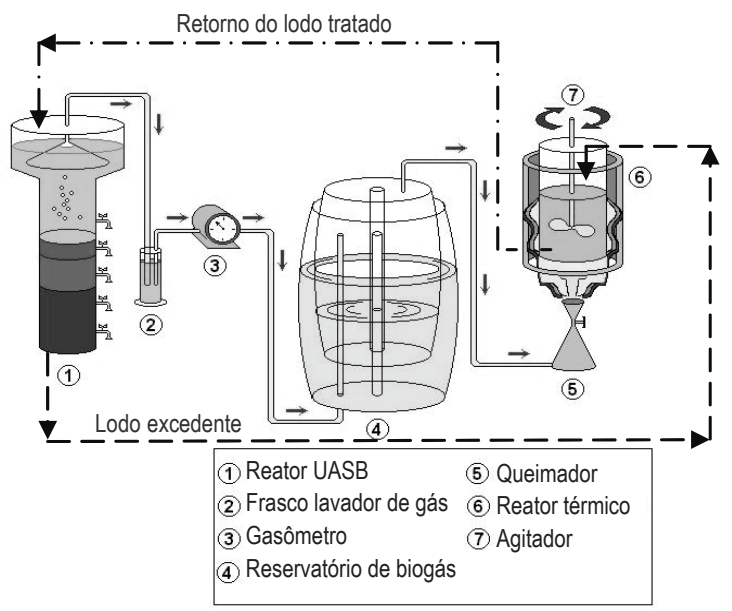

Figura 1 - Representação esquemática do aparato experimental: (A) sistema de tratamento de esgotos; (B) sistema de tratamento térmico de lodo 
Tabela 2 - Principais características e dados operacionais do reator UASB (valores médios)

\begin{tabular}{|c|c|c|c|c|c|c|}
\hline Vazão (L.h-1) & $\begin{array}{c}\text { Temperatura } \\
\text { operacional }\left({ }^{\circ} \mathrm{C}\right)\end{array}$ & TDH (h) & DQO afluente (mg. $\left.\mathrm{L}^{-1}\right)$ & Concentração do lodo (\%) & $\begin{array}{l}\text { Produção de } \\
\text { biogás }\left(\text { L.d } d^{-1}\right)\end{array}$ & $\begin{array}{l}\text { Coeficiente de } \\
\text { produção de lodo } \\
\left(\text { gST.gDQO }_{\text {aplicada }}^{-1}\right)\end{array}$ \\
\hline 74 & 25 & 5,6 & 540 & 4 & 200 & 0,15 \\
\hline
\end{tabular}

Tabela 3 - Principais características do aparato experimental

\begin{tabular}{|c|c|c|c|c|c|}
\hline \multirow{2}{*}{ Característica } & \multicolumn{3}{|c|}{ Reator UASB } & \multirow{2}{*}{$\begin{array}{l}\text { Reservatório de } \\
\text { biogás }\end{array}$} & \multirow{2}{*}{ Reator térmico } \\
\hline & Compartimento de digestão & Compartimento de decantação & Total & & \\
\hline Material & Acrílico & Fibra de vidro & - & Polietileno & Aço \\
\hline Diâmetro (m) & 0,3 & 0,30 a 0,50 & - & 0,5 & 0,15 \\
\hline Altura (m) & 3 & 1 & 4 & 0,7 & 0,3 \\
\hline Volume útil (L) & 212 & 204 & 416 & 110 & 5 \\
\hline
\end{tabular}

\section{Operação das unidades experimentais}

Como o biogás é produzido continuamente e o descarte do lodo é realizado em bateladas, almejando-se atingir as condições de trabalho desejadas, armazenou-se o biogás para posterior queima no momento do tratamento térmico do lodo. Este armazenamento, a pressões finais situadas entre 5,5 e 6,5 cm de coluna d'água, propiciou alcançar temperaturas mais elevadas em períodos de tempo mais curtos, empregando-se a pressão de reservação no decorrer do processo de queima.

No decorrer dos ensaios, o lodo foi mantido em constante agitação, objetivando-se minimizar a sedimentação de sólidos e a formação de gradiente de temperatura ao longo da altura do volume de lodo aquecido, uma vez que o queimador do biogás foi instalado sob o reator térmico. O tratamento térmico do lodo foi iniciado somente após homogeneização e coleta da primeira amostra, sendo as amostras seguintes coletadas após 1,5, 3,0, 5,0 e 7,0 horas. Utilizou-se somente o biogás como fonte de energia, tendo sido monitorados o tempo e a temperatura no decorrer do processo de tratamento térmico do lodo.

O volume de biogás, armazenado e utilizado em cada teste, sempre correspondeu à produção ocorrida em 24 horas (em média, próxima a 200 L/dia). O volume de lodo descartado para tratamento térmico (aproximadamente 4,3 L, a uma concentração média em torno de 4,0\%) também sempre correspondeu à produção média de um dia, sendo estimado a partir do coeficiente de produção de sólidos do sistema.

\section{Recirculação do lodo tratado termicamente}

A avaliação do efeito do retorno do lodo tratado termicamente sobre o desempenho do reator UASB foi realizada preliminarmente, tomando-se como parâmetros de desempenho a taxa de produção de biogás e as concentrações de DQO total, SST e turbidez no efluente final. Tais parâmetros foram avaliados no dia anterior ao retorno do lodo, no decorrer do dia em que aconteceu o retorno do lodo e no dia posterior ao término do retorno do lodo. Embora o lodo tenha sido tratado termicamente em batelada, o retorno do mesmo ao reator foi efetuado num período de 24 horas, de modo a atenuar eventuais sobrecargas.

Foram realizados três ensaios com a alimentação da vazão afluente ao reator UASB em regime transiente, isto é, variável ao longo do dia, simulando um hidrograma típico horário, todavia correspondendo a uma vazão média de 74 L/h (TDH médio igual a 5,6 horas). Outros três ensaios foram realizados com alimentação da vazão afluente ao reator realizada em regime constante (TDH constante igual a 5,6 horas). Todos os resultados foram obtidos a partir de amostras compostas proporcionais coletadas no decorrer de 24 horas.

\section{Testes estatísticos}

Testes estatísticos de análises de significância entre médias e variâncias foram aplicados para se determinar o efeito dos diferentes tempos e temperaturas de aquecimento sobre as variações das concentrações de $\mathrm{DBO}$ do lodo tratado termicamente. Os testes aplicados foram o teste $\chi^{2}$, o teste $t$ de Student, o teste F e o teste U de MannWhitney. Complementarmente, realizou-se a Análise de Variância (ANOVA), a qual permite verificar se determinado fator produz mudanças em uma variável de interesse.

\section{Resultados e Discussão}

\section{Efeito do tratamento térmico sobre a biodegradabilidade aeróbia do lodo}

Os resultados de temperatura DBO total (obtidos pelo método Oxitop ${ }^{\circledR}$ ) e DBO filtrada (obtidos pelo método titulométrico), apresentados na Tabela 4, correspondem ao término de cada intervalo de aquecimento, ou seja, ao momento em que foram coletadas as amostras de lodo no interior do reator térmico. 
As Figuras 2 e 4 apresentam o comportamento de todos os resultados obtidos para o parâmetro DBO a partir das duas metodologias aplicadas, as quais indicam valores máximo, mínimo, quartil inferior (25\%), quartil superior (75\%) e a mediana. As Figuras 3 e 5 apresentam o comportamento deste mesmo parâmetro, juntamente com a temperatura, a partir dos valores médios, também para as duas metodologias aplicadas.

Analisando-se as Figuras 2 e 3, que apresentam os resultados de DBO obtidos a partir do método titulométrico, e a Tabela 4, percebese, tanto nos valores médios quanto na apresentação gráfica do comportamento de todos os valores obtidos, uma variação crescente referente à concentração da DBO entre as amostras coletadas em tempos e temperaturas de aquecimento diferentes. Tal fato é também percebido nos resultados obtidos a partir do Sistema Oxitop ${ }^{\circledR}$ de análise de DBO, cujos resultados são apresentados nas Figuras 4 e 5 e também na Tabela 4. Como todas as amostras, dentro de cada metodologia, foram submetidas às mesmas condições de ensaio, tendo variado somente os tempos e as temperaturas de coleta, tais resultados indicam uma relação direta entre a melhora da biodegradabilidade do lodo e os parâmetros tempo e temperatura de ensaio, o que indica que o lodo torna-se mais biodegradável à medida que aumentam o tempo e a temperatura de aquecimento.

As diferenças nas concentrações de DBO entre as amostras coletadas em temperatura ambiente e as amostras submetidas ao tratamento térmico foram também confirmadas a partir dos testes estatísticos realizados, como mostram os resultados dos testes de significância entre médias e variâncias nas Tabelas 5 e 6 .

Adicionalmente, a análise de variância confirmou que a variável "tempo de aquecimento" exerceu influência na variação da DBO filtrada das amostras de lodo submetidas ao tratamento térmico, conforme apresentado na Tabela 7.

Os resultados apresentados anteriormente estão de acordo com aqueles apresentados por Borges e Chernicharo (no prelo) sobre os parâmetros "proteínas", "carboidratos", "lipídeos" e "DQO", os quais indicaram uma maior biodisponibilidade da fração orgânica para uma possível posterior etapa de degradação biológica. Embora em diferentes escalas, essa maior biodisponibilidade, visualizada a partir dos parâmetros anteriormente citados, refletiu nos resultados de $\mathrm{DBO}$, os quais representam, portanto, a maior biodisponibilidade traduzida em uma maior biodegradabilidade.

Ademais, percebe-se que o aumento da DBO se deu de maneira distribuída e uniforme, parecendo, inclusive, seguir o aumento da temperatura desde o início ao final do aquecimento. Tal fato pode ser verificado na Tabela 4, na qual, por exemplo, no método titulométrico, os valores médios de DBO filtrada variaram de $52 \mathrm{mg} / \mathrm{L}$ na amostra coletada sem aquecimento, atingiram $1.044 \mathrm{mg} / \mathrm{L}$ na amostra aquecida por 1,5 hora e $3.163 \mathrm{mg} / \mathrm{L}$ na amostra submetida a 7 horas de aquecimento. Estes valores são, respectivamente, cerca de 20 e 61 vezes maiores do que o valor médio de DBO verificado na amostra que não
Tabela 4 - Estatística descritiva das concentrações de Demanda Bioquímica de Oxigênio (DBO)

\begin{tabular}{lccccc}
$\begin{array}{l}\text { Tempo de aquecimento } \\
\text { (horas) }\end{array}$ & 0 & 1,5 & 3 & 5 & 7 \\
Temperatura ( ${ }^{\circ} \mathrm{C}$ ) & 25 & 50 & 64 & 72 & 74 \\
$\begin{array}{l}\text { Amostras filtradas (DBO filtrada } \mathrm{mg} / \mathrm{L} \text { ) } \\
\text { Método titulométrico }\end{array}$ & & & & \\
Número de amostras & 9 & 7 & 9 & 9 & 9 \\
Média & 52 & 1.044 & 2.315 & 2.866 & 3.163 \\
Máximo & 77 & 1.809 & 3.321 & 3.822 & 4.311 \\
Mínimo & 18 & 393 & 1.344 & 1.479 & 1.831 \\
Desvio padrão & 18 & 559 & 586 & 694 & 723 \\
Aumento (Número de vezes) & 1 & 20 & 45 & 56 & 61 \\
Amostras brutas (DBO total $\mathrm{mg} / \mathrm{L}$ ) & & & & & \\
Sistema Oxitop ${ }^{\circledR}$ & & & & & \\
Número de amostras & 10 & 10 & 10 & 10 & 10 \\
Média & 11.683 & 12.948 & 14.078 & 14.561 & 15.338 \\
Máximo & 16.729 & 17.439 & 19.969 & 22.659 & 21.109 \\
Mínimo & 6.969 & 6.302 & 8.028 & 8.298 & 7.448 \\
Desvio padrão & 3.557 & 4.459 & 4.612 & 5.041 & 5.201 \\
Variação (\%) & 0 & 11 & 21 & 25 & 31 \\
\hline
\end{tabular}

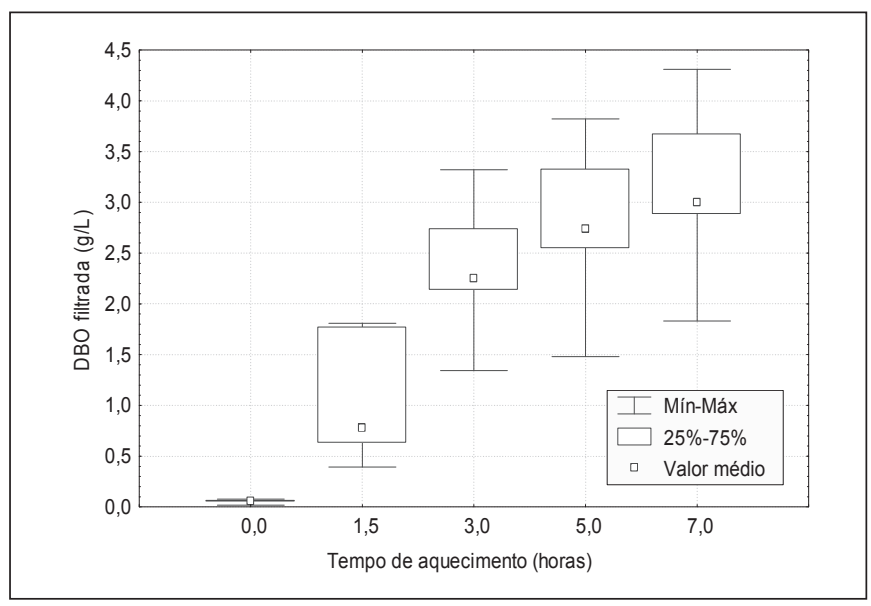

Figura 2 - Variação da DBO (Método titulométrico)

foi aquecida. No método manométrico de ensaio, os valores médios de DBO variaram de $11.683 \mathrm{mg} / \mathrm{L}$, na amostra que não sofreu aquecimento, a $12.948 \mathrm{mg} / \mathrm{L}$, na amostra aquecida durante 1,5 hora, e 15.338 mg. L $^{-1}$ na amostra submetida a 7 horas de aquecimento. Tais valores são, respectivamente, cerca de 11 e $31 \%$ mais altos do que o valor médio verificado na amostra que não foi submetida a aquecimento. Visto que os resultados obtidos apresentam um aumento expressivo, esse fato reforça a indicação de aumento da biodegradabilidade da fração orgânica a partir do tratamento térmico do lodo.

Na Figura 6, são apresentadas relações $\mathrm{DBO}_{5} / \mathrm{DQO}$ obtidas a partir dos resultados das amostras filtradas. É possível observar a tendência de elevação desta relação com o aumento do tempo de aquecimento, o que indica a desintegração da matéria orgânica (maior biodisponibilidade) e a maior biodegradabilidade do material presente no lodo submetido ao tratamento térmico. 


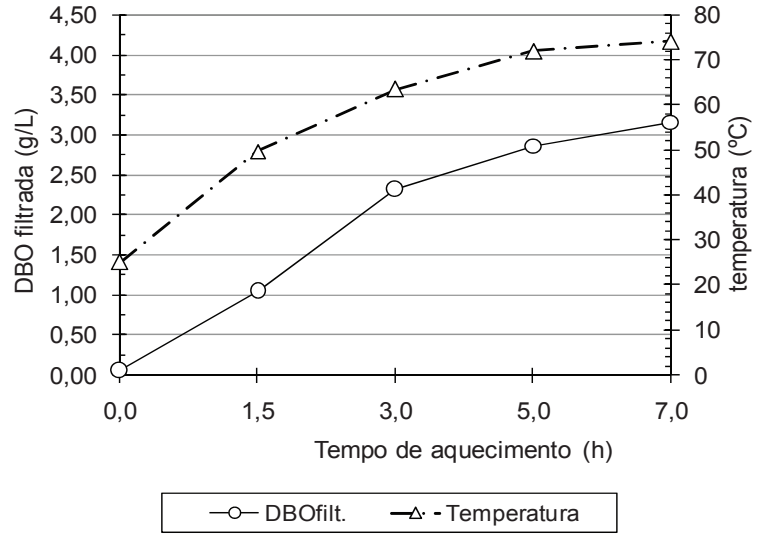

Figura 3 - Variação da DBO e da temperatura. Valores médios (Método titulométrico)

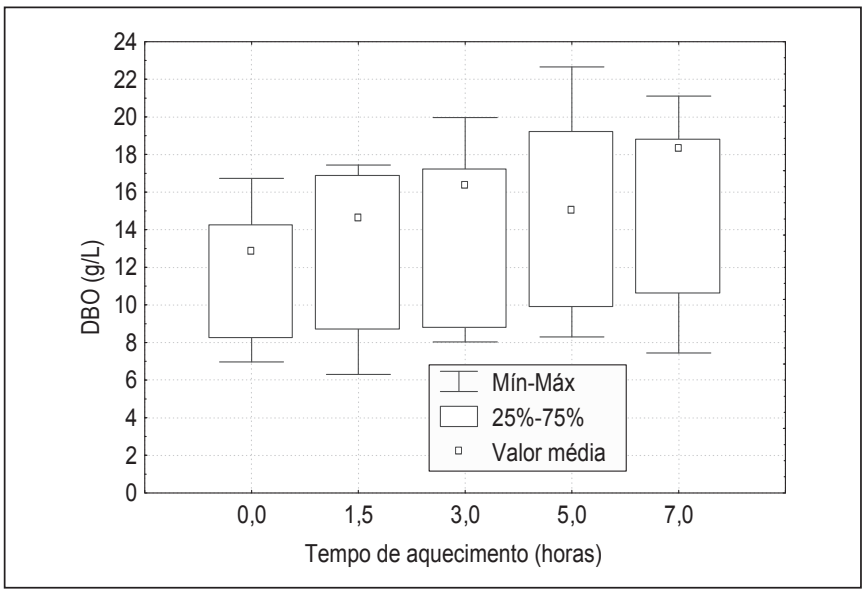

Figura 4 - Variação da DBO total (Sistema Oxitop $\left.{ }^{\circledR}\right)$

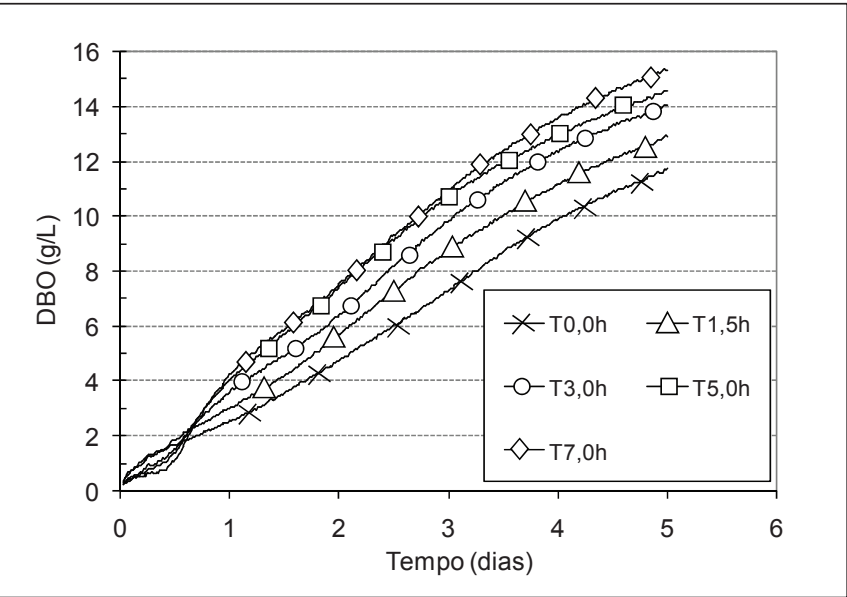

Figura 5 - Curvas médias de variação da DBO total, com o tempo e a temperatura (Sistema Oxitop ${ }^{\circledR}$ )

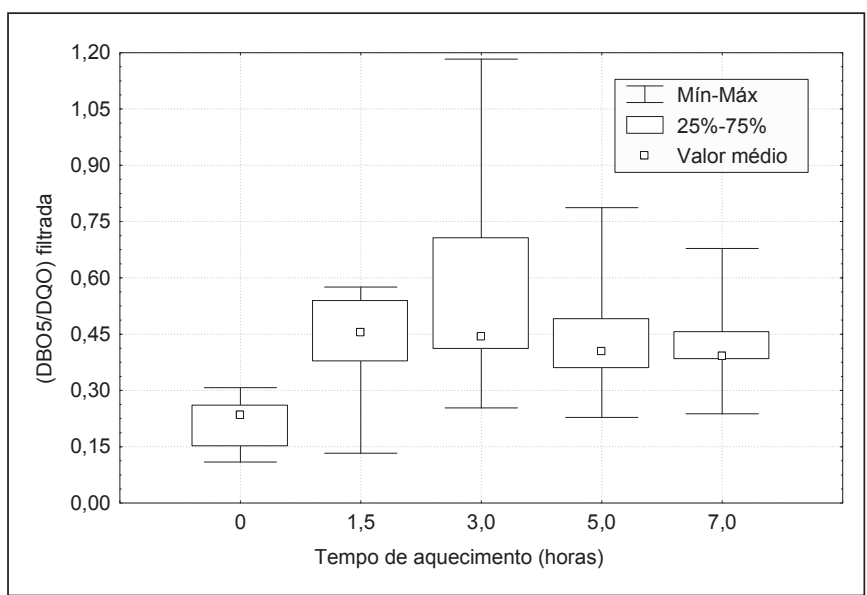

Figura 6 - Variação da relação DBO/5Q0 (amostras filtradas)

Tabela 5 - Resumo dos testes de significância entre médias (DBO), de amostras coletadas antes do tratamento térmico (T0,0h) e após sete horas de tratamento térmico $(\mathrm{T} 7,0 \mathrm{~h})$

\begin{tabular}{lccccc} 
Parâmetros & Nível de & T (calculado) & T (tabelado) & $\mathrm{H}_{0}$ & Conclusão \\
DBO filtrada $-t$ de Student $(\mathrm{T} 0,0 \mathrm{~h}-\mathrm{T} 7,0 \mathrm{~h})$ & $\alpha=0,05$ & $-12,96$ & 2,12 & Rejeitar & $\mu_{1} \neq \mu_{2}$ \\
DBO total - Mann-Whitney (T0,0h - T7,0h) & $\alpha=0,05$ & 1,81 & 1,96 & Aceitar & $\mu_{1}=\mu_{2}$ \\
\hline DBO total - Mann-Whitney (T0,0h - T7,0h) & $\alpha=0,10$ & 1,81 & 1,645 & Rejeitar & $\mu_{1} \neq \mu_{2}$ \\
\hline
\end{tabular}

Observação: DBO filtrada (Método titulométrico); DBO total (Método manométrico, Sistema Oxitop ${ }^{\circledR}$ ).

Tabela 6 - Resumo dos testes de significância entre variâncias (DBO) de amostras coletadas antes do tratamento térmico (T0,0h) e após sete horas de tratamento térmico $(\mathrm{T} 7,0 \mathrm{~h})$ : teste $\mathrm{F}$

\begin{tabular}{|c|c|c|c|c|c|c|}
\hline \multirow{2}{*}{ Parâmetros } & \multirow{2}{*}{ Nível de significância } & \multirow{2}{*}{ F (calculado) } & \multicolumn{2}{|c|}{ F (tabelado) } & \multirow{2}{*}{$\mathrm{H}_{0}$} & \multirow{2}{*}{ Conclusão } \\
\hline & & & Inferior & Superior & & \\
\hline DBO filtrada (T0,0h - T7,0h) & $\alpha=0,05$ & 0,001 & 0,23 & 4,43 & Rejeitar & $\mathrm{S}_{1}^{2} \neq \mathrm{S}_{2}^{2}$ \\
\hline
\end{tabular}

Observação: o teste $\mathrm{F}$ se aplica somente para grupo de amostras que seguem uma distribuição normal.

Tabela 7 - Resumo da Análise de Variância (ANOVA)

\begin{tabular}{lccccc} 
Variável dependente & Variável independente & F (calculado) & $F$ (tabelado) & Ho & Conclusão \\
DBO filtrada & Tempo de aquecimento & 9,63 & 2,62 & Rejeitar & $\begin{array}{l}\text { A variável independente causa efeito } \\
\text { sobre a variável dependente. }\end{array}$ \\
\hline
\end{tabular}

Observação: o teste ANOVA se aplica somente para grupo de amostras que seguem uma distribuição normal. 
Portanto, os resultados do presente trabalho indicam o efeito positivo do tratamento térmico sobre a fração orgânica do lodo, mesmo a baixas temperaturas. Tais resultados estão de acordo com o trabalho de Muller (2001), que defende a aplicação de algum método de desintegração para se alcançar uma maior estabilização de lodos, especialmente anaeróbios, uma vez que o potencial de ganhos adicionais na decomposição biológica da matéria orgânica é bastante baixo. Ainda, conforme este mesmo autor, a desintegração dos sólidos aumenta a solubilidade da matéria orgânica, permitindo uma maior eficiência em sua remoção.

\section{Efeito do tratamento térmico sobre a biodegradabilidade anaeróbia do lodo}

Embora o teste de DBO permita a avaliação da biodegradabilidade de uma amostra, o ideal, em situações nas quais se almeja conhecer a biodegradabilidade anaeróbia de um lodo, seria a aplicação de um teste em condições anaeróbias. Neste sentido, implementou-se também a operação do Sistema Oxitop ${ }^{\circledR}$ para testes de biodegradabilidade em condições anaeróbias, cujos resultados são apresentados na Tabela 8 e na Figura 7.

Analisando-se os dados apresentados na Tabela 8 e na Figura 7 , verifica-se uma maior produção de biogás nas amostras de lodo que foram submetidas a 7 horas de tratamento térmico em comparação à produção de biogás resultante das amostras que foram submetidas à degradação tal como eram descartadas do reator, ou seja, sem tratamento térmico. Tais resultados, nos quais as amostras referentes a 0,0 e 7,0 horas de aquecimento são substratos orgânicos a serem degradados, indicam, portanto, uma maior biodegradabilidade do lodo submetido ao tratamento térmico também a partir dos ensaios realizados em condições anaeróbias de degradação. Esses resultados são coerentes com aqueles apresentados anteriormente referentes às análises de DBO, explicitando o incremento das características de biodegradabilidade do lodo submetido ao tratamento térmico.

\section{Efeito do retorno do lodo tratado termicamente para o reator UASB}

Embora os resultados apresentados anteriormente tenham demonstrado o aumento tanto da biodegradabilidade aeróbia quanto da biodegradabilidade anaeróbia do lodo tratado termicamente, buscouse avaliar também, ainda que preliminarmente, o efeito do retorno do lodo tratado termicamente sobre o desempenho do reator UASB com base nas alterações dos parâmetros DQO total, SST e turbidez no efluente do reator, e da taxa de produção de biogás. As Figuras 8 a 15 mostram os resultados médios dos monitoramentos realizados em três momentos distintos: no dia anterior ao retorno do lodo, no dia em que se praticou o retorno do lodo e no dia posterior ao término
Tabela 8 - Estatística descritiva dos resultados de produção de biogás

\begin{tabular}{|c|c|c|}
\hline Tempo de aquecimento (horas) & 0 & 7 \\
\hline Temperatura $\left({ }^{\circ} \mathrm{C}\right)$ & 25 & 74 \\
\hline \multicolumn{3}{|c|}{ Biogás produzido $(\mathrm{mL})^{*}$} \\
\hline Número de amostras & 3 & 3 \\
\hline Média & 312 & 468 \\
\hline Máximo & 437 & 627 \\
\hline Mínimo & 139 & 387 \\
\hline Desvio padrão & 155 & 137 \\
\hline Variação (\%) & 0 & 50 \\
\hline
\end{tabular}

Observação: resultados referentes ao volume de biogás medido após cinco dias de ensaio.

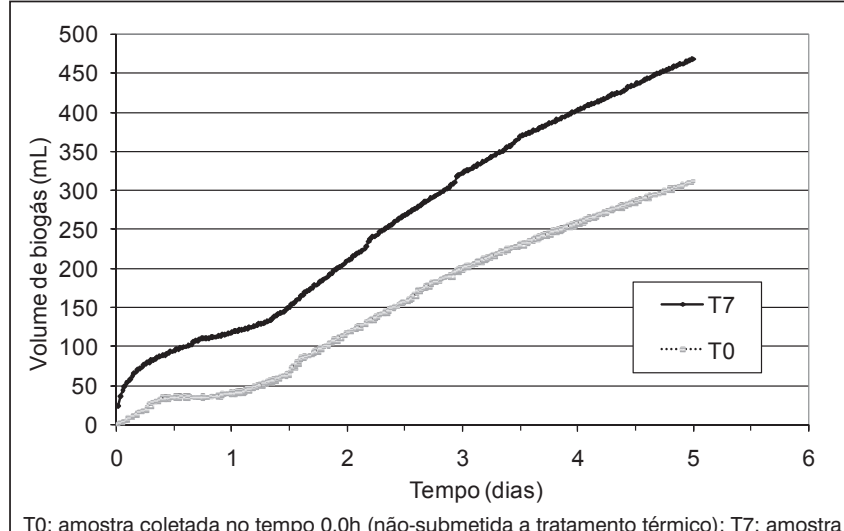

T0: amostra coletada no tempo 0,0h (não-submetida a tratamento térmico); T7: amostra coletada após 7,0 h de tratamento térmico.

Figura 7 - Produção de biogás nos testes de biodegradabilidade anaeróbia (resultados médios)

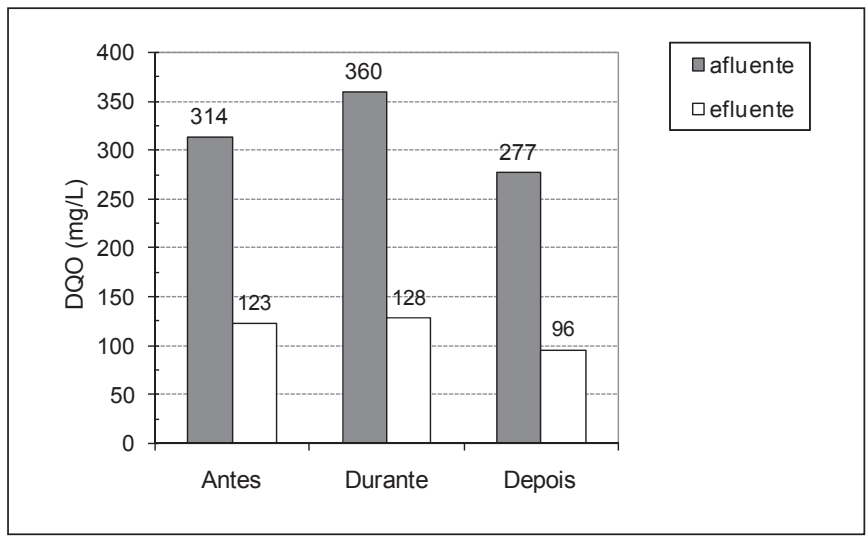

Figura 8 - Resultados médios de DQO total obtidos com a alimentação do reator UASB em regime transiente de vazão

do retorno do lodo. Para cada parâmetro monitorado, são mostrados, inicialmente, os resultados médios dos três testes realizados com o reator alimentado em regime transiente de vazão e, posteriormente, os resultados dos outros três testes realizados com a alimentação com vazão constante.

As Figuras 8 a 11 mostram que o comportamento dos parâmetros "DQO total" e "SST" foi bastante semelhante em ambos os testes (com vazão transiente e vazão constante), podendo-se observar o aumento da concentração no afluente no dia em que se praticou o retorno do 
lodo, e praticamente nenhuma alteração na concentração efluente. Como se esperava, o aumento das concentrações afluentes de DQO e de SST verificadas no segundo dia de monitoramento se deve à carga adicional decorrente do retorno do lodo tratado termicamente. A manutenção dos mesmos níveis de qualidade do efluente nos dias em que se praticou o retorno de lodo, e também no dia seguinte,

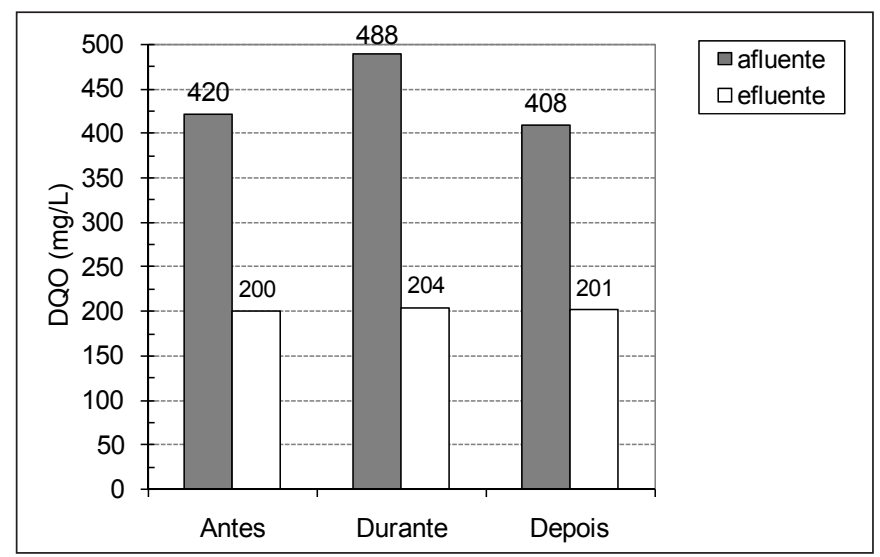

Figura 9 - Resultados médios de DQO total obtidos com a alimentação do reator UASB em regime constante de vazão

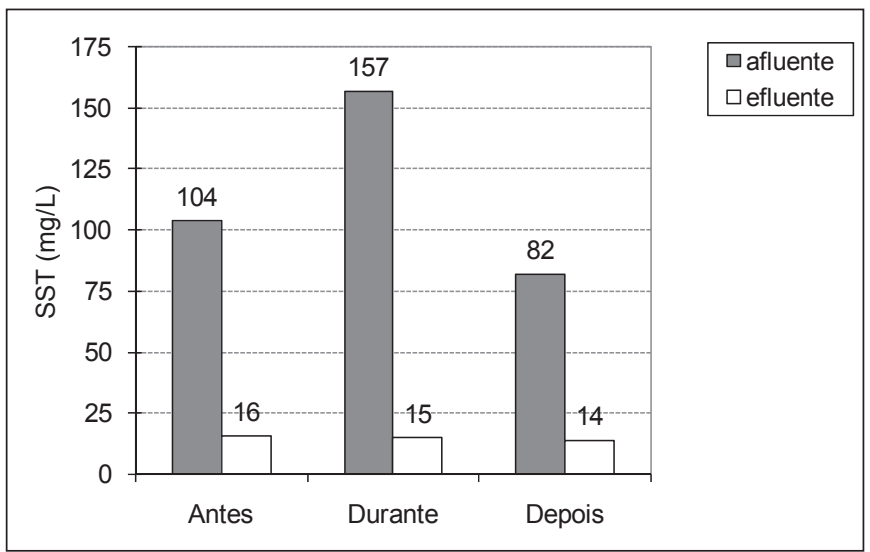

Figura 10 - Resultados médios de SST obtidos com a alimentação do reator UASB em regime transiente de vazão

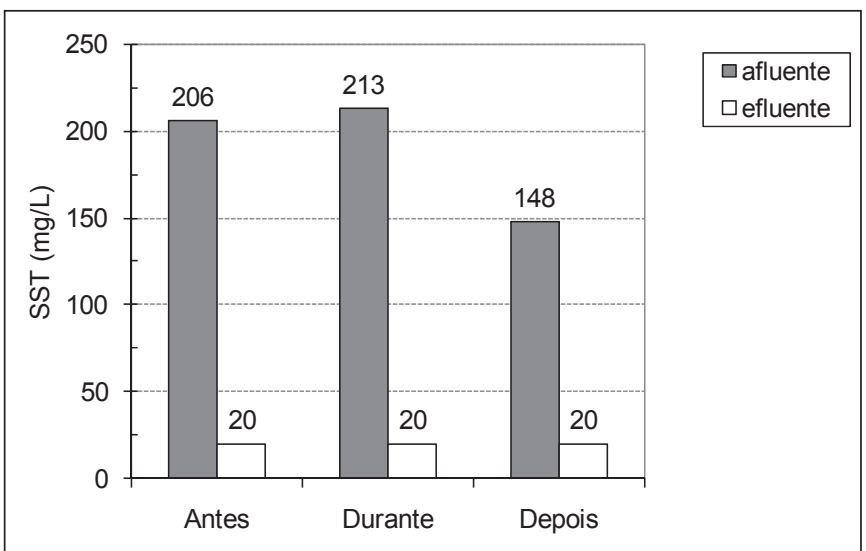

Figura 11 - Resultados médios de SST obtidos com a alimentação do reator UASB com vazão constante demonstram que as cargas adicionais de DQO e SST foram devidamente assimiladas pelo reator.

Diferentemente do que se observou para os parâmetros "DQO" e "SST" (Figuras 8 a 11), o parâmetro turbidez (Figuras 12 e 13) apresentou uma elevação no dia em que se praticou o retorno de lodo, mas apenas no teste realizado com a vazão transiente.

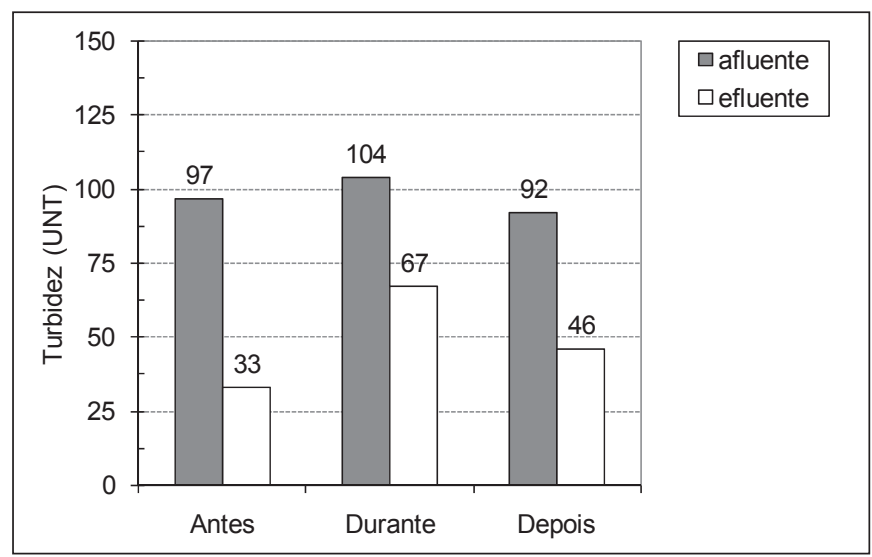

Figura 12 - Resultados médios de turbidez obtidos com a alimentação do reator UASB em regime transiente de vazão

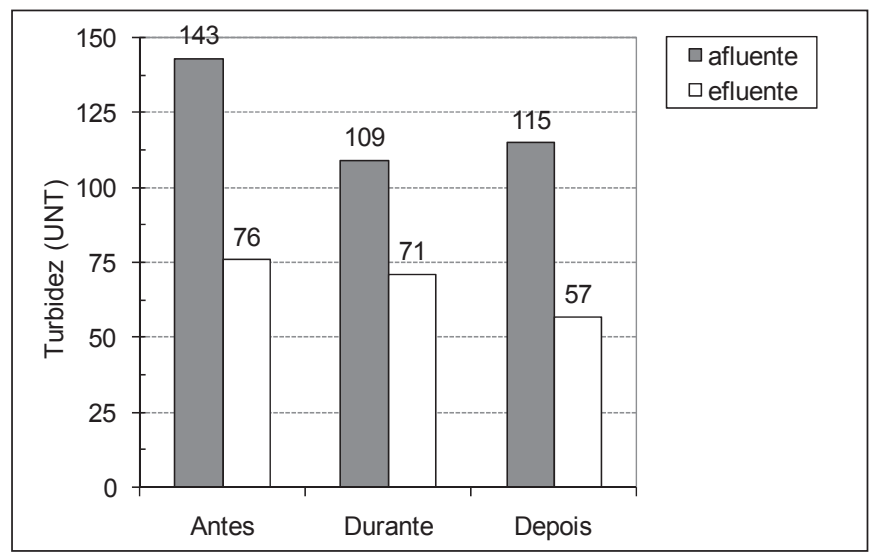

Figura 13 - Resultados médios de turbidez obtidos com a alimentação do reator UASB com vazão constante

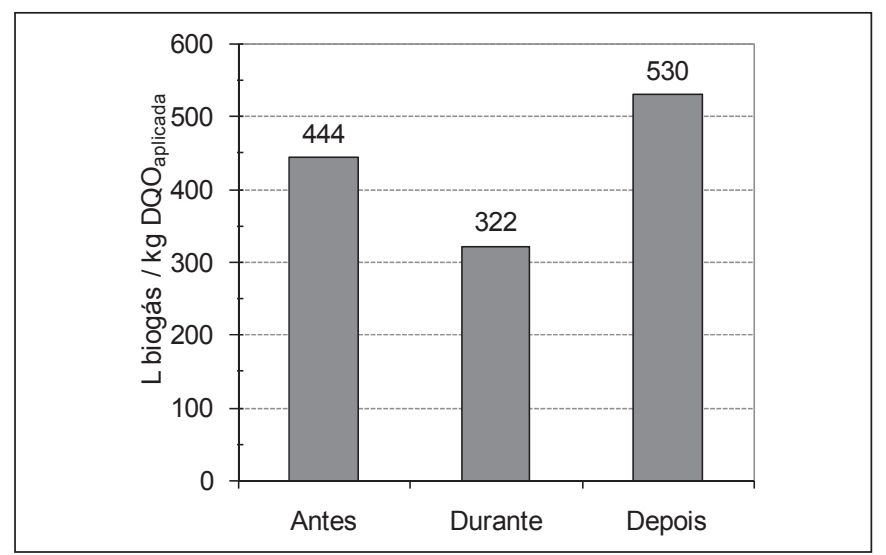

Figura 14 - Resultados médios de produção de biogás obtidos com a alimentação do reator UASB em regime transiente de vazão 
Comportamento semelhante foi relatado por França (2002), que observou o escurecimento e a elevada perda de sólidos no efluente de um reator UASB após uma hora do retorno do lodo tratado termicamente. Ressalta-se, no entanto, que tal retorno (França, 2002) foi efetuado no decorrer de apenas quatro horas, podendo ter ocorrido um choque de carga hidráulica e orgânica no reator UASB. Diferentemente, na presente pesquisa, o retorno do lodo tratado termicamente foi realizado de forma gradual no decorrer de 24 horas, o que propiciou uma melhor distribuição da carga orgânica ao longo do tempo, o que pode ter sido a razão de o reator UASB ser capaz de absorver as cargas aplicadas.

Os resultados referentes à taxa de produção de biogás (Figuras 14 e 15) confirmam o que já havia sido observado para o parâmetro DQO: a carga orgânica adicional, decorrente do retorno do lodo tratado termicamente, foi devidamente assimilada pelo reator e convertida em biogás. Em todos os testes realizados, ocorreu o aumento da produção de biogás no dia subsequente ao retorno do lodo.

A análise conjunta dos resultados apresentados anteriormente é também indicativa do aumento da biodegradabilidade do lodo submetido ao tratamento térmico. Portanto, além do benefício direto da maior remoção da matéria orgânica presente no esgoto bruto, tem-se o incremento da geração de biogás no sistema, em consonância com os resultados obtidos por Sorensen, Tholstrup e Andreasen (1999). Estudo semelhante foi desenvolvido por Parsekian e Pires (2002), todavia com o emprego da lise celular a partir da tecnologia de ultrassom. O lodo submetido ao processo de lise celular era também recirculado para um reator UASB, que teve sua eficiência de remoção de DQO aumentada. A qualidade do efluente final do sistema também permaneceu inalterada.

\section{Conclusões}

O uso do biogás gerado em reatores UASB apresenta-se, com base na metodologia de trabalho desenvolvida, como uma fonte de energia autossustentável para o tratamento térmico do lodo anaeróbio excedente, permitindo o alcance de temperaturas próximas a $75^{\circ} \mathrm{C}$, após 7 horas do início do processo de aquecimento do lodo. Essas condições de temperatura e tempo de tratamento térmico foram suficientes para promover:

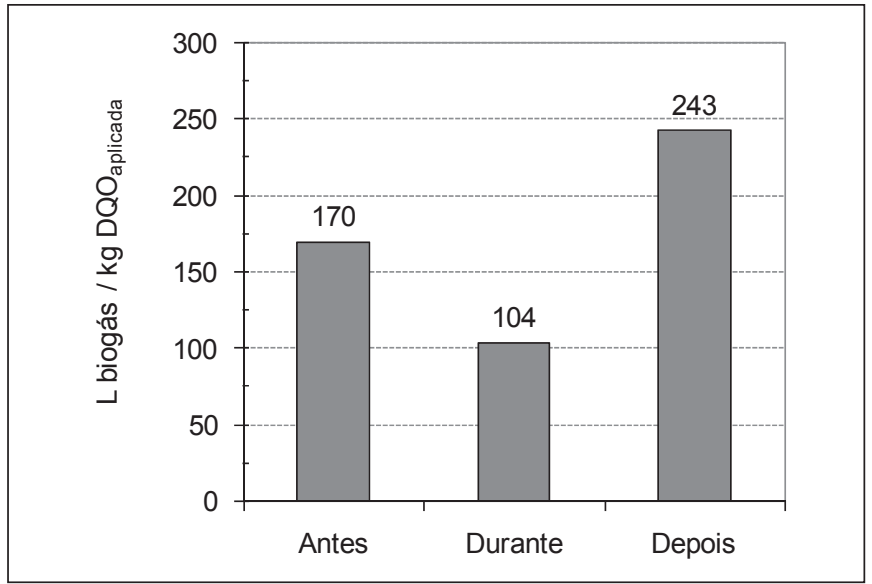

Figura 15 - Resultados médios de produção de biogás obtidos com a alimentação do reator UASB com vazão constante

- a desintegração térmica da fração orgânica presente no lodo anaeróbio submetido ao tratamento;

- incrementos estatisticamente significativos nas características de biodegradabilidade da fração orgânica presente no lodo, permitindo aumentos de cerca de 60 vezes na DBO filtrada, e de cerca de 30\% na DBO total;

- um aumento de cerca de 50\% nas características de biodegradabilidade anaeróbia da fração orgânica presente no lodo;

- um aumento na taxa de produção de biogás, mantendo-se ainda a qualidade do efluente quando o lodo tratado termicamente foi retornado para o reator UASB.

Tais resultados indicam o aumento da biodegradabilidade do lodo, promovendo importantes ganhos em termos de eficiência e produção de energia do sistema.

\section{Agradecimentos}

Os autores agradecem à Financiadora de Estudos e Projetos/ Programa de Pesquisas em Saneamento Básico (Finep/Prosab) e à Fundação de Amparo à Pesquisa do Estado de Minas Gerais (Fapemig), pelo apoio financeiro à pesquisa, ao Conselho Nacional de Desenvolvimento Científico e Tecnológico (CNPq), pela bolsa de doutorado de Eduardo Sales Machado Borges, e à Companhia de Saneamento de Minas Gerais (COPASA), pela constante contribuição no decorrer do trabalho.

\section{Referências}

APHA/AWWA/WEF. Standard Methods for the examination of water and wastewater. 20. ed. Washington DC: APHA, 1998.
BORGES, E.S.M. Tratamento térmico de lodo anaeróbio a partir da queima do biogás produzido em reator UASB objetivando a higienização 
e a melhoria da biodisponibilidade e biodegradabilidade da fração orgânica. 254f. Tese (Doutorado em Saneamento, Meio Ambiente e Recursos hídricos) - Escola de Engenharia, Universidade Federal de Minas Gerais, Belo Horizonte, 2004.

BORGES, E.S.M.; CHERNICHARO, C.A.L. Effect of thermal treatment of anaerobic sludge on the bioavailability and biodegradability characteristics of the organic fraction. Brazilian Journal of Chemical Engineering, (no prelo).

BOUGRIER, C.; DELGENÈS, J.P.; CARRÈRE, H. Effects of thermal treatments on five different waste actived sludge samples solubilisation, physical properties and anaerobic digestion. Chemical Engineering Journal, v. 139. p. 236-244, 2008.

Combination of thermal treatments and anaerobic digestion to reduce sewage sludge quantity and improve biogas yield. Process Safety and Environmental Protection, v. 84, n. B4, p. 280-284, 2006.

BOUGRIER, C. et al. Effect of ultrasonic, thermal and ozone pre-treatment on waste active sludge solubilisation and anaerobic biodegradability. Chemical Engineering and Processing, v. 45, n. 8, p. 711-718, 2006.

DELERIS, S. et al. Minimization of sludge production in biological processes: an alternative solution for the problem of sludge disposal. In: Specialised Conference on Sludge Management: regulation, treatment, utilisation and disposal, Acapulco: IWA, 2001. p. 486-493.

DOHANYOS, M. et al. Improvement of anaerobic digestion of sludge. Water Science and Technology, v. 49, n. 10, p. 89-96, 2004.

EVANS, G. Biowaste and biological waste treatment. London: James \& James Scienc Publishers Ltd., 2001.

FERRER, I. et al. Increasing biogas production by thermal $\left(70^{\circ} \mathrm{C}\right)$ sludge pre-treatment prior to thermophilic anaerobic digestion. Biochemical Engineering Journal, v. 42, p. 186-192, 2008

FORESTI, E.; ZAIAT, M.; VALLERO, M. Anaerobic processes as the core technology for sustainable domestic wastewater treatment: Consolidated applications, new trends, perspectives, and challenges. Reviews in Environmental Science and Bio/Technology, v. 5, p. 3-19, 2006.

FRANÇA, M. Avaliação da biodegradabilidade e da biodisponibilidade do lodo de esgoto anaeróbio termohidrolisado pelo uso do biogás. 154f. Dissertação (Mestrado em Engenharia Ambiental) - Setor de Engenharia Sanitária e Ambiental, Universidade Federal de Santa Catarina, Florianópolis, 2002.

GAVALA, H.N. et al. Mesophilic and thermophilic anaerobic digestion of primary and secondary sludge. Effect of pre-treatment at elevated temperature. Water Research, v. 37, p. 4561-4572, 2003.

et al. Mesophilic and thermophilic anaerobic digestion of primary and secondary sludge. Effect of the pre-treatment at 70o C. In: VII Taller y Simposio Latinoamericano Sobre Digestión Anaerobia, Yucatán: Memorias. Posters, IWA, p. 270-273, 2002.

IPCC. Climate Change 2001: the scientific basis. Contribution of Working Group I to the Third Assessment Report of the Intergovernmental Panel on Climate Change. In: HOUGHTON, J.T. et al (Ed.). Cambridge University Press: Cambridge, UK and New York, NY USA, 2001.
KEPP, U.; SOLHEIM, O.E. Meeting increased demands on sludge quality - Experience with full scale plant for thermal disintegration. In: World Congress Anaerobic Digestion, Antwerpen: Anaerobic Conversion for Sustainability. Proceedings - Part 2, p. 523-525, 2001

$\mathrm{KIM}$, J. et al. Effects of various pretreatments for enhanced anaerobic digestion with waste activated sludge. Journal of Bioscience and Bioengineering, v. 95, n. 3, p. 271-275, 2003.

LU, J. et al. Improving anaerobic sewage sludge digestion by implementation of a hyper-thermophilic prehydrolysis step. Journal of Environmental Management, v. 88, n. 4, p. 881-889, 2008.

MULDER, A. Optimization of the methane recovery from anaerobic treatment sewage. In: World Congress Anaerobic Digestion, Antwerpen: Anaerobic Conversion for Sustainability. Proceedings - Part 2, p. 617619,2001

MULLER, J.A. Prospects and problems of sludge pre-treatment processes. Water Science and Technology. v. 44, n. 10, p. 121-128, 2001.

NOYOLA, A. et al. digestão e Higienização de lodos de estação de tratamento de esgotos através de um processo de duas fases não convencionais. In: XXIV CONGRESSO BRASILEIRO DE ENGENHARIA SANITÁRIA E AMBIENTAL. Anais eletrônicos. Belo Horizonte: ABES, 2007.

PAGLIUSO, J.D.; PASSIG, F.H.; VILLELA L.C.H. Odour treatment and energy recovery in anaerobic sewage treatment plants. In: VII Taller y Simposio Latinoamericano Sobre Digestión Anaerobia, Yucatán: Memorias. Trabajos Orales, IWA, p. 553-560, 2002.

PARSEKIAN, M.P.S.; PIRES, E.C. Avaliação do emprego da lise celular forçada em sistema anaeróbio/aeróbio no tratamento de esgoto sanitário sintético. In: VII Taller y Simposio Latinoamericano Sobre Digestión Anaerobia, Yucatán: Memorias. Posters, IWA, p. 297-300, 2002.

ROCHER, M. et al. Towards a reduction in excess sludge production in activated sludge processes: biomass physicochemical treatment and biodegradation. Applied Microbiology and Biotechnology, v. 51, p. 883890,1999

SORENSEN, J; THOLSTRUP, G; ANDREASEN, K. Anaerobic digestion and thermal hydrolysis to reduce production of sludge. 1999. Disponivel em: <http://www.cambi.no/wip4/publications.epl?cat=10644>. Acesso em: 23 nov 2000

VALO, A.; CARRÈRE, H.; DELGENĖS, J.P. Thermal, chemical and thermo-chemical pre-treatment of waste active sludge for anaerobic digestion. Journal of Chemical Technology and Biotechnology, v. 79, p. 1197-1203, 2004

VAN HAANDEL, A.C.; LETTINGA, G. Tratamento anaeróbio de esgotos: um manual para regiões de clima quente. Campina Grande: Fotolitos e Impressão Gráfica OFF-SET, 1994.

WTW. Determination of the biological biodegradability of organic substances under anaerobic conditions using the Oxitop Control measuring system. 1999 